Please quote as: Janson, A.; Söllner, M. \& Leimeister, J. M. (2017): The Impact of Procedural Scaffolding on Mobile Learning Outcomes. In: Academy of Management Annual Meeting (AOM). Atlanta, Georgia, USA. 


\title{
The Impact of Procedural Scaffolding on Mobile Learning Outcomes
}

\author{
Authors \\ Andreas Janson', Matthias Sölner ${ }^{1,2}$, Jan Marco Leimeister ${ }^{1,2}$ \\ ${ }^{1}$ University of Kassel \\ Information Systems, Research Center for IS Design (ITeG) \\ Pfannkuchstr. 1, 34121 Kassel, Germany \\ E-Mail: [andreas.janson, soellner, leimeister]@uni-kassel.de \\ ${ }^{2}$ University of St. Gallen \\ Institute of Information Management \\ Müller-Friedberg-Str. 8, 9000 St. Gallen, Switzerland \\ E-Mail: [matthias.soellner, janmarco.leimeister] @unisg.ch
}

\section{Acknowledgements:}

Our thanks go to all participating students of the Yizheng Technician College and the Hefei Vocational and Technical College, Sissy-Josefina Ernst for her effort in implementing the mobile learning application MoKe ("ㅆobile Kompetenzentwicklung”), as well as Maike Holzmüller and Marian Thiel de Gafenco without whose support the study would not have been possible. The research presented in this paper was partially funded by the German Federal Ministry of Education and Research in the course of the project kuLtig (www.projekt-kuLtig.de), Grant No. 01BEX05A13 and the project ExTEND (www.projekt-ExTEND.de), Grant No. 01FJ15127. 


\title{
The Impact of Procedural Scaffolding on Mobile Learning Outcomes
}

\begin{abstract}
Mobile learning, offering anytime and anywhere learning, is becoming increasingly important in various areas such as the training of blue-collar workers in organizations. However, mobile learning may overwhelm the learner since it is often used in rich physical environments and demands a high self-regulated learning ability. Therefore, research suggests the use of procedural scaffolds to guide the learner and to enhance learning outcomes. To investigate how different procedural scaffolds contribute to learning outcomes, we conducted a between-subject quasiexperiment with 333 Chinese blue-collar workers. Our results show that comprehensive tutorials at the beginning of the learning process have a positive influence on learning outcomes in contrast to instructional overlays during the learning process as well as a combination of both scaffolds. Consequently, we did not observe that procedural scaffolds per se have a positive impact on learning outcomes, but the right scaffold in the right context has the potential to increase learning outcomes.
\end{abstract}

\section{Keywords:}

Technology-Mediated Learning; Mobile Learning; Scaffolding 